\title{
ADOLESCENTES NA AMÉRICA LATINA: ENCARANDO O FUTURO COM CETICISMO
}

\author{
ADOLESCENTS IN LATINAMERICA: FACING THE \\ FUTURE WITH SKEPTICISM
}

Lúcia de Mello e Souza Lehmann

WELTI, Carlos. Adolescents in LatinAmerica: Facing lhe Future with Skepticism (pp.276-306). In BROWN, Bradford, LAWSON, Reed \& SARASWATHI, T.S. (Eds.). The world syouth: Adolescence in eight regions of lhe globe. Cambridge: Cambridge University Press, 2002.376 pp; Hardback, ISBN 052180910X; Paperback, ISBN 0521006058.

O texto "Adolescentes na América Latina”, escrito por Carlos Welti, faz parte do livro intitulado "O Mundo do Jovem: Adolescência em Oito Regiões do Globo". O livro é resultado de um trabalho realizado pelo Grupo de Estudo sobre a Adolescência no Séc. $\mathrm{XXI}^{2}$, e contou com a participação de pesquisadores internacionais, buscando estabelecer os possíveis cenários de vida dos adolescentes. Retrata o trabalho de pesquisa realizado em diferentes regiões do mundo, procurando identificar e analisar as condições atuais de vida dos adolescentes bem como as possibilidades para um futuro próximo, dentro das realides específicas de cada região. tem como objetivo focalizar a duração da adolescência, como esta é vivenciada e se distingue como um estado de vida. Analisa as trajetórias de vidas dos adolescentes, as influências exercidas pelas sociedades em que vivem e as perspectivas e expectativas dos adolescentes em relação ao futuro.

O capítulo intitulado "Adolescentes na América Latina - Encarando o Futuro com Ceticismo", aqui focalizado, desenvolve-se pontuando as mudanças sociais da região, aspectos demográficos, condições econômicas, relações familiares, relações entre jovens, educaçao, emprego, saúde e, $\mathrm{V}^{\wedge}$ lo^lenc $\wedge$ la e part $\wedge 1 \mathrm{c} \wedge 1$ pação política.

O autor inicia o texto referindo-se a uma pesquisa da UNICEF (2000) a qual retrata que os jovens da América Latina acreditam que terão melhores oportunidades no futuro que seus pais, mas consideram que seus próprios países serão os piores lugares para viver. Acrescenta que a maior parte dos jovens não tem confiança nas instituições governa- mentais, e que a violência e a insegurança são as suas maiores fontes de inquietação. Estas constelações levam o autor a afirmar que seu texto traz uma visão pessimista em relação à juventude da América Latina. Devido à falta de informações recentes de algumas regiões, o autor utiliza-se de censos de pesquisa de alguns países como representativos da região. Focaliza principalmente os adolescentes entre 15 e 19 anos de idade, esclarecendo, no entanto que, na América Latina, a adolescência inicia cedo e se estende, em alguns segmentos, até a idade de 25 anos. Entre os mais pobres, a falta de oportunidades praticainente elimina este estágio da vida.

Temas como sexo, gravidez precoce, uso de drogas, violência, circunscreveram os poucos estudos sobre o adolescente latino-americano após 1960. Para o autor, duas situações específicas justificam seu estudo do jovem da região: a continuidade de crescimento em termos demográficos (em termos reais e relativo aos outros segmentos) e também o crescimento do desemprego neste grupo. Atribui o crescimento da população jovem à diminuição da fertilidade e ao aumento da expectativa de vida, tornando evidente a adolescência como uma fase intermediária entre ser criança e ser adulto. A redução da participação da juventude na atividade econômica e o crescimento do desemprego se tornaram um destaque do final Século XX nessa Região. Estimase que o número de jovens entre 15 e 24 anos na América Latina será de 161 milhões no ano de 2030 (CE-LADE). Após, espera-se uma redução da taxa de crescimento que deverá se refletir na diminuição da demanda dos serviços educacionais e empregos.

1 Psicóloga. Doutora em Psicologia Social pela Universidade Federal do Rio de Janeiro- $\mathrm{U}^{\wedge} \mathrm{F} \wedge \mathrm{R} \wedge \mathrm{J}$. $\mathrm{R} \wedge \mathrm{D} / \mathrm{CNPq}$ na Escola de Educação da Universidade Federal do Estado do Rio de Janeiro-UN^IR^IO - coordenadora da pesquisa "A imagem corporal do jovem: corpo, género e inclusão”.

2 O grupo de estudos foi constituído por pesquisadores de diferentes regiões e coordenado por Reed W. Larson com a colaboração de Jeylan T. Mortimer e B. Bradford. Recebeu apoio da W.T. Grant Foundation, da Johann Jacobs Foundation e do Carnegie Adolescente Forum. Duas resenhas do mesmo livro, uma enfocando a adolescência na África e outra o capitulo final, foram anteriormente publicadas na RBCDH, respectivamente nos números 13(1) e 13(2). 
Comprova-se um aumento da expectativa de vida; no entanto, jovens da Guatemala ou Haiti viverão em média 10 anos menos do que na Costa Rica ou Cuba, o que demonstra diferentes chances de sobrevivência, dadas as condições de saúde na infância, acesso aos serviços básicos e exposição à violência. No que diz respeito às condições econômicas, as crises continuam afetando a vida da população, dificultando melhoras para as novas gerações. Ajustamentos e medidas econômicas, tomadas pelos governos, têm reduzido os gastos destinados às áreas sociais, à educação e à saúde, o que atinge especialmente os jovens, que têm vivido crises durante toda a sua vida.

Os processos sociais, marcados de paradoxos, são, no entender do autor, os que mais diretamente afetam os adolescentes nas últimas décadas: A) A revolução sexual aumentou o risco de gravidez e das doenças sexualmente transmissíveis, enquanto o uso de modernos contraceptivos diminuiu a extensão destes riscos. B) A expectativa de vida aumentou nos últimos anos; no entanto, os acidentes e a violência se tornaram as maiores causas de morte entre os jovens. C) A juventude tem alcançado altos níveis de educação, especialmente a população feminina, mas tem diminuído a oferta de empregos. Estabelece-se um paradoxo e as universidades produzem jovens desempregados, com altos níveis educacionais. D) No que diz respeito à saúde, as últimas décadas têm experimentado uma redução significativa de doenças infecciosas e outros problemas que afetam as crianças, diminuindo a mortalidade infantil. No entanto, doenças como a AIDS emergiram com efeitos altamente significativos para o segmento jovem. O aumento do número de fumantes entre adolescentes, o consumo de álcool e outras drogas, como a cocaína, se tornam mais difundidos. E) No aspecto político, as formas democráticas de governo vêm ocupando o lugar dos regimes autoritários, mas a participação do jovem é pouca ou nenhuma. A apatia e falta de confiança na política caracteriza as suas atitudes. Os adolescentes de classe média têm expressado sua participação por meio de pequenos grupos defendendo a privatização de serviços e a universidade pública. As mudanças sociais na região também se refletem na forma com que a religião participa na vida dos jovens. Importante aspecto da tradição latino-americana, a religião católica assiste aos avanços do Protestantismo. As instituições religiosas, Católicas e Evangélicas, exerceram, segundo o autor, importante função na estabilidade política dos países, ao suportarem o regime militar que, como a igreja, opunha-se ao marxismo. Contudo, o movimento surgido dentro da igreja católica, a Teologia da Libertação, aparece como uma alternativa para mudanças na região. A influência religiosa tem diminuído entre os adolescentes, que vêem as instituições religiosas longe de seus problemas cotidianos, e contra questões importantes de seu interesse como a liberdade sexual, concubinato, métodos anticoncepcionais, aborto etc. O autor aborda ainda as transformações ocorridas nas relações familiares e as relações entre os próprios jovens, que se mostram intensificadas, a partir de afinidades como esportes, tipos de música, modos de se vestir e se comportar. Alguns grupos se organizam também em torno de atividades violentas, formando gangs.

A violência constitui-se um problema central da América Latina, apontada pela Organização Panamericana de Saúde como sendo uma das áreas mais violentas do mundo. Países como a Colômbia, Porto Rico, Venezuela e, lamentavelmente, o Brasil, apresentam as maiores taxas de mortalidade entre jovens masculinos entre 15 e 24 anos. A violência entre os adolescentes chega à escola causando a morte de alunos e professores. As condições sociais como a pobreza, problemas familiares, acesso a drogas, têm contribuído para o crescimento da violência. Além disso, o jovem encontra trabalho no mundo do crime, o que se torna uma alternativa de sobrevivência.

O autor conclui o texto destacando os seguintes pontos: 1) A adolescência é um tempo de planos e expectativas de vida, mas as dificuldades de acesso a niveis elevados de educação e oportunidades de emprego criam uma reação de frustração em muitos jovens. 2) A religião não exerce mais, como no passado, uma influência significativa sobre o jovem, especialmente em relação ao comportamento sexual e ao casamento. 3) A violência envolvendo jovens é um fenômeno crescente na região, tornando-se um problema público. A solução para o futuro da região depende de um aumento significativo de jovens adultos bem educados, saudáveis e economicamente produtivos, o que implica em investimento nas crianças e jovens, especialmente as mulheres. Para o autor, a população jovem desta região é uma geração sem esperança, e a sociedade que não der atenção a esta juventude não terá futuro.

O trabalho de Carlos Welti retrata e analisa ajuventude na América Latina com precisão de grande conhecedor. A extensão e diversidade cultural da região o impedem de se deter mais especificamente sobre cada pais, mas revela os profundos paradoxos que assolam a região.O subtítulo, encarando o futuro com ceticismo, reflete a situação dramática enfrentada pelos jovens frente a tamanhas dificuldades e perspectivas que se mostram extremamente limitadas se mantidas as políticas atuais da região. O autor parece compartilhar do sentimento de frustração e desesperança que encontrou em muitos jovens, ao confessar o pessimismo em seu texto. Embora o trabalho poucas vezes se refira especificamente ao Brasil, podemos dizer que seu desenho e a análise se aproximam imensamente do vivenciado pela juventude brasileira como um todo. 